\title{
Was it Merely a Coincidence? Towards a Practice-Based Perspective on Early Internationalisation of SMEs
}

\author{
Zofia Patora-Wysocka
}

\section{A B S T R A C T}

Objective: The aim of this article is to analyse the relation between some aspects of reflexive actions and routinisation within the internationalisation process. The article provides a new insight into the phenomenon of early internationalisation of small and medium-sized enterprises.

Research Design \& Methods: The qualitative research offers an alternative approach to the problem of how enterprises explore foreign opportunities in the realms of daily performed activities. The research is based on the practice-based orientation. That perspective explores the concepts of everyday actions and practice in the realms of routine dynamics field of studies.

Findings: The qualitative research provides a framework of the relation between various types of reflexive actions, and their routinisation, as well as the internationalisation of everyday practice.

Implications \& Recommendations: This study explores the practice-based perspective on IE and the early internationalisation process of textile and apparel enterprises. This work contributes to the deeper understanding of the early internationalisation process and it sheds some new light on its potential explanatory categories. The notion of daily activities may be perceived as important units of analysis in management.

Contribution \& Value Added: The analysis of everyday activities of early internationalisation of SMEs may comprise here a promising research area and therefore, a 'theoretical bridge' between the practice-based perspective and IE may develop.

Article type: research article

Keywords:

textile and apparel enterprises; integration of pre-existing theoretical JEL codes: L20, L21, L26

Received: 14 June 2018 Revised: 12 October 2018 Accepted: 16 November 2018

\section{Suggested citation:}

Patora-Wysocka, Z. (2018). Was it Merely a Coincidence? Towards a Practice-based Perspective on Early Internationalisation of SMEs. Entrepreneurial Business and Economics Review, 6(4), 87-101. https://doi.org/10.15678/EBER.2018.060405 


\section{INTRODUCTION}

This study explores the practice-based perspective on IE and the early internationalisation process of textile and apparel enterprises. The phenomenon of early internationalisation of small and medium-sized enterprises (SMEs) has attracted a growing research interest over the past years (Amorós, Basco, \& Romaní, 2016). The international entrepreneurship (IE) literature on early internationalisation tackles a vast number of aspects of entrepreneurial activity on foreign markets. Entrepreneurship in its basic meaning puts emphasis on 'individual opportunistic activity that creates value and bears risk and is strongly associated with innovation' (Styles \& Seymour, 2006, p. 127), thereby one may presume there is a link between IE and approaches that explore the phenomena of daily activities in organisation and management studies. The 'big issues' of IE include finding, seizing and exploiting opportunities, as well as gaining knowledge and experience (Oviatt \& McDougall, 2005) and operating under uncertainty, risk and barriers to SMEs' internationalisation (Baum, Schwens, \& Kabst, 2011). Thus, there is little empirical research examining how everyday activities can shape early internationalisation. This study fills this important gap in the literature, and in particular shows the relationships between reflexive and routine activities with regard to the early internationalisation process.

The notion of reflexivity is related to intentional as well as heuristic activities (Makowski, 2016). Everyday activities may be of different character - some are routinely reproduced and some are taken in an unplanned manner. Thus, I differentiate between 'high' and 'low' extent of reflexivity of activities recreated daily. The clearer the goal representation, the more intense the reflexivity of activities is. However, at times, the intentionality of actions is incoherent with their results. Therefore, the qualitative research illustrates the thesis that there are differences in the reflexive activities that influence the process of early internationalisation. Therefore, 'high' reflexivity can go in pair with spontaneity of activities, especially where the early internationalisation is concerned. On the other hand, relatively low reflexivity of activities takes place when it comes to unintended situations or routinely reproduced activities. Still, that kind of acting can be of purposive character when we look at the overall practice reproduction. This article seeks to examine in further detail how the reflexivity opens up everyday stream of activities to change in the context of internationalisation. Consequently, it specifies the relation between reflexive and routine actions within the everyday practice in the internationalisation process of textile and apparel SMEs.

The research is based on the practice-based orientation. That perspective explores the concepts of everyday actions and practice in the realms of routine dynamics field of studies (Feldman, Pentland, D’Adderio, \& Lazaric, 2016). Organisational processes take place on the everyday level of recursive individual as well as collective activities that are anchored in the entrepreneurship and internationalisation issues. Therefore, the qualitative research was conducted during four in-depth interviews in three enterprises from the textile and apparel industry.

Tracing the efforts to analyse and synthesise the growing body of issues tackled under the domain of international entrepreneurship (IE), we may see that IE highlights the importance of agency and human actions, innovation, learning, creativity, opportunism, as well as organisational change and strategic management. Whereas these problems 
are of recurring research importance in internationalisation and practice-based studies, in a more general view they relate to teleological activities as well as the problem of forming organisational goals in random situations and contingencies. The practice-based approach may develop the 'theoretical bridge' between the IE's issues and the problem of everyday routines and practice in SMEs. In order to place the relation between routine and reflexive actions in the realms of early internationalisation process, the literature review explores the potential common aspects of the two perspectives. The qualitative research offers an alternative approach to the problem of how enterprises explore opportunities abroad in the context of their everyday activities. It provides a framework of the relation between various types of reflexive actions, and their routinisation, as well as the internationalisation of everyday practice.

The first section of the article introduces the concepts of routines and reflexive actions in the practice - based perspective. Afterwards, there is a literature review conducted towards the processual orientation in IE. The second, empirical section of the article introduces methods and a framework of the relation between various aspects of reflexive actions, routinisation, and internationalisation in the realms of everyday practice. The final section is devoted to results and discussion. The article is closed by conclusion.

\section{LITERATURE REVIEW}

The key categories in the practice-based perspective are routine activities and everyday practice. The notion of routine is well established in organisation and management studies. The notion of routine denotes 'repetitive, recognizable patterns of interdependent action, carried out by multiple actors' (Feldman \& Pentland, 2003, p. 95). Although there is a lack of agreement about the notion of routine, this theoretical concept is widely recognized as it opens to the notion of action. Still, routine definitions have limited impact on our understanding of how reflexive actions result in the reproduction of routines or the emergence of new activity patterns.

When actors perform activities using their discursive knowledge, there is a chance to change the stream of activities purposefully. The bundles of routines involve multiple interdependent actions. That calls for the reconsideration of 'technocratic thinking' that involves following purely rational and individually formed goals. The practice-based lens considers routines and capabilities as collective categories that are produced, reproduced and developed in the process of evolution. To put it in a nutshell, routines may be of the emergent character, and their effects may also be of emergent nature. However, it is highly important to notice that emergence of routines is not about their change but rather about 'the occurrence of new ones' (Stańczyk-Hugiet, Piórkowska, \& Stańczyk, 2017, p. 540).

Plans, expectations and even clearly defined goals are instantiated in an endeavour of practice, interactions and situational dependence. In terms of interdependency between actions and actors and mutual constitution of routine schemas there is a relational approach to the routine dynamics (Deken, Carlile, Berends, \& Lauche, 2016). This framework relates to: i) 'novelty' that is related to past experiences of actors and, therefore, their different interpretation of what is novel in a specific situation; ii) 'dependence' that refers to the consequences of activities for other actions; and iii) 'difference' that concerns various understandings of ostensive patterns of routines (e.g. templates, procedures), as well as different experiences and interests (Deken et al., 2016, p. 662). 
Putting these premises into the practice-based perspective we get a twofold question about the relation between routine and reflexive actions, and therefore, the intentional and emergent process of forming and pursuing goals in everyday practice in organisations. Dittrich, Guérard, and Seidl (2016) show how reflective talk enables the change of daily routines. The role of a single unit of action is questioned for the sake of collective actions embraced in practice. There have been three aspects of collective reflexion put forth in the context of everyday talk in practice-based studies (Dittrich et al., 2016). These are: '1) naming and situating problems or opportunities with regard to the performative and ostensive aspects of the routine; 2 ) jointly envisaging and exploring alternative ways of enacting the routine; 3 ) evaluating and questioning these ways from different angles' (Dittrich et al., 2016, p. 2). All of these aspects resemble intentional searching for a solution instead of following plans in a rigid way.

I assume that these are the modes of reflexive acting that are present in everyday stream of practice. Although, for analytical reasons, I explore separately modes of reflexive acting, it may be presumed that in contextual situations some of them prevail as well as work together. Therefore, I identify three aspects of reflexive actions: 1) 'acting through analogy' that is a way to manage rapid-change situations (Gavetti, Levinthal, \& Rivkin, 2005 , p. 693). Using analogy cognitively limits the situatedness, and the newness of context (Goffman, 1959). In this sense, acting through analogy may serve as a dynamic mechanism generative of practice emergence. 2) 'Controlled creation', one of the premises of routine dynamics states that activities reproduced daily 'can consistently produce novel work' (Pentland \& Jung, 2016, p. 509). When a situation is undefined, actors need to put new brackets on organisational reality. It may be done by rapid but intended and defined change of recurring practice (Schumpeter, 1934, 'creative destruction') or by controlled directing actions towards new yet clearly visualised situations. Such modes of reflexive acting give rise to routines and daily actions as the locus of innovations. 3) Intentional seeking: as long as outcomes of routines are not pure results of intentions. Actors consciously monitor their routines, envisage different alternatives and explore opportunities. Intentional seeking may be a starting point in new practice emergence.

Summing up, we may presume that teleological activities are of great importance in management theory and practice. Meanwhile, interactions between multiple actors and artefacts, sometimes contradictory intentions and motives, are the background for accomplishing interdependent activities on a daily basis. Actors might pursue their daily routine activities in direct routine performances without clearly defined goals or they may spontaneously engage in changing a stream of activities.

Traditionally, IE put entrepreneurial characteristics and processes in the context of the institutional forms of internationalisation. However, the recent reviews show a growing concern about the bias toward the institutional aspects of internationalisation and postulate the return to the basic concepts of IE that are rooted in entrepreneurial orientation (Etemad, 2015). Tracing the efforts to analyse and synthesise the growing body of issues tackled under the domain of international entrepreneurship (IE) there are striking postulates of the return to the very basic concepts of IE that are rooted in entrepreneurial orientation (EO) (Thurner, Gershman, \& Roud, 2015).The very basic attributes of entrepreneurship are 'innovativeness, pro-activeness, and risk-taking' (Miller, 1983), as well as 'competitive aggressiveness and autonomy' (Etemad, 2015, p. 90). 
Keupp and Gassmann (2009) proposed to put at the same level of analysis the research questions from the IB and IE domains. Both fields tackle the 'how' and 'why' questions, however, IB is more focused on the firms as basic units of analysis in terms of creating value and gaining competitive advantage on international markets. On the other hand, at the centre of IE research questions stands the problem of exploitation of opportunities as well as innovation, learning and creativity. Looking closer at the characteristic research issues common for the IB and IE fields, a 'how' question is worth attention as long as it emphasises the processual nature of international performance.

There is a clear analogy between IE and practice-based studies in terms of the issues tackled. Entrepreneurship may be perceived as a stream of activities and if it comes down to international or global context, we may understand it as activities of gaining, creating and redefining practical knowledge in the international dimension. Entrepreneurial activities are about 'jumping at opportunities' and simultaneously they may be of projective and intentional or planned character. In fact, in the IE literature, there is a vast number of works tackling the problems of uncertainty and risk-seeking behaviour (Liesch, Welch, \& Buckley, 2011); motivation and past experience (Amorós et al., 2016); human action and entrepreneurship (Styles \& Seymour, 2006); creativity (Autio, 2005); networks (Thurner et al., 2015); as well as the timing dimension (Aspelund \& Moen, 2005). These are the aspects that direct the mode of decision taking in terms of internationalisation of an enterprise. The activities taken in order to internationalise are the results of the situational context and unpredictability, the necessities or opportunities that drive entrepreneurs to take new activities abroad, creativity, the web of interactions, the experience of past activities, as well the time pressure.

IE can be thus informed by the premises or practice-based theories that analyse the relation between activities performed on a daily basis and aspects of their change. Therefore, internationalisation is a kind of generative mechanism of activity patterns. Under situational and contextual circumstances, it can result in activity pattern reproduction, a rapid change or even disappearance of activity.

\section{MATERIAL AND METHODS}

For this study I used the data collected during four in-depth interviews in three enterprises from the textile and apparel industry in Lodz Province. The Gamma enterprise has been manufacturing denim clothes for over ten years for other brands in the women, men and children apparel industry. It cooperates with various fabric and service suppliers, such as denim laundries as well as embroidery shops and manufacturers. The Theta is the youngest of the interviewed enterprises, and at the same time it is a renowned fashion brand on the Polish market and it makes early attempts to internationalise. The main product of the brand is a T-shirt with a characteristic imprint. The Zeta enterprise is doing the inward processing. Nowadays, its customers are often premium fashion brands. When it was launched over 20 years ago it was operating mainly locally. However, at the very beginning it started to seek opportunities to develop abroad.

The methods I used comprised non-participatory observations of daily working routines and semi-structured interviews with entrepreneurs who were the (co-)owners of the enterprises. In some parts of the interviews the entrepreneurs asked their co-workers to 
participate. In such cases, the owners decided to ask the co-workers to talk about the details of a particular issue or they asked them to demonstrate some parts of processes. The elicitation capabilities of the interviewer are of great importance for the richness as well as the overall quality of the data (Hamil, 2014). Therefore, in order to enrich the data, I reacted in an open, responsive manner each time I was offered a possibility of learn new details from the person directly involved in situations or processes. The methodological consequence of such situations was that the coded empirical material received an annotation of the source of additional information.

There were unified guidelines for the interviews, however, in the course of the interviews I followed the threads that were developed by entrepreneurs. The preliminary part of interviews was devoted to understanding the characteristics of a given enterprise, while the main part was focused on the product development in relation to internationalisation. Interviews were from one to two hours long and they were voice-recorded, and later transcribed. After each of the interviews I took additional notes.

During the data analysis I codified the text material. The data were coded manually using printed copies of the transcribed materials, which included notes and highlights in the texts. Coding is more about 'linking' than 'labelling' (Saladaňa, 2013, p. 8), therefore, during the data analysis procedure I took the iterative approach. In the first step, I read the transcribed material in order to understand its general meaning. After that, I looked for the most general research aspects that were supplemented with additional notes. Then, data were read very carefully, word by word, in order to highlight the phrases that are important for the very first impressions and observations. Simultaneously, I did continuous literature research. This was the preliminary stage of the coding process. I applied provisional coding, which is an appropriate method when a researcher tends to establish 'a start list' of codes that can be 'revised, modified, deleted, or expanded to include new codes' (Saladaňa, 2013, p. 121). During that time, I was recurrently making sense of the initial empirical findings through constant literature review. When I built the initial framework of the phenomena explored (I called it the institutionalisation of spontaneous actions), I started to reconfigure the initially developed codes into a more general list of categories. Since the purpose of my study was to find the repetitive activity schemas and meaning of the developed categories, I used pattern coding (Saladaňa, 2013). The process of institutionalisation of spontaneous activities provides a broader background for the aspects of reflexive and routine activities in the internationalisation that are tackled in this article. Consequently, this study explores three processual categories of the relation between reflexive and routine activities in the early internationalisation process i.e.: i) the reflexivity of actions; ii) the variability of routines reproduced in the course of internationalisation; iii) the results of new practice emergence/practice reproduction. The thematically leading category of 'the reflexivity of actions' has three other subcategories developed.

The reliability of this research is based on the logical consistency of the categories developed across cases. However, as long as there is divergence between the cases in terms of context, experience, occurrences, and individual people involved, there are similar dimensions of the process of institutionalisation of spontaneous activities in the realms of internationalisation. 


\section{RESULTS AND DISCUSSION}

As a result of the qualitative research, an alternative approach to the issue of how enterprises explore internationalisation opportunities in everyday practice was proposed. The research offers a framework of the relation between various aspects of reflexive actions, routinisation, and internationalisation in the realms of everyday practice. There are identified three aspects that distinguish the reflexivity of actions: 1) acting through analogy, 2) controlled creation, and 3 ) intentional seeking (Table 1).

A conceptual framework of the relation between routine and reflexive actions within everyday practice is marked by at least three dimensions of the phenomena. Based on the earlier theoretical analysis as well as on continuously made observations there are some empirical categories conceptualised: i) the reflexivity of actions; ii) the variability of routines reproduced in the course of internationalisation; iii) the results of new practice emergence/practice reproduction.

We may presume that daily activities are of a different level of reflexivity. Reflexivity may be of unequal 'extent', as it relates to conscious monitoring (Giddens, 1984) and intentional or heuristic orientation (Dittrich et al., 2016). There are different modes of acting (analogy, controlled creation, and intentional seeking) related to differences in the reflexivity of activities. Therefore, we may presume that there are 'high', 'medium' and 'low' extents of the reflexivity of activities.

Relatively low reflexivity of activities is when entrepreneurs meet new and unexpected contextual circumstances. In order to limit the newness of a situation entrepreneurs may act through analogy that is related to their past experience. In line with analogy the attempts go to simplify the situational newness and then, to asses relatively quickly if a situation is worth involving people, resources, knowledge, and capital. In terms of involving in new internationalisation activities, low reflexivity of actions meets the adaptation capabilities of an enterprise. Indeed, the low reflexivity does not eliminate the purposive character of undertaking new activities. The higher 'levels' of reflexivity are invoked post factum (Weick, 1995), when the results of actions may be evaluated. The question is if we may associate the enterprise that has accumulated experience with a kind of early internationalisation in case when it starts to operate in a new business area. Therefore, the problem of learning through different spillovers and capabilities is crucially important for the decision of being internationalised early (García-Cabrera, García-Soto, \& Suárez-Ortega, 2017). However, learning is based on experience, and thus, analogy, regardless of whether we gain it in domestic or foreign circumstances.

On the contrary, high reflexivity of activities is when the entrepreneur has clearly defined goals in terms of internationalisation already at the beginning of his or her operating in the market. Still, in the stream of everyday reproduced practice, the results of intended activities are unknown and high reflexivity can go in line with opportunism, heuristic orientation and intentional seeking of solutions to problems.

Medium reflexivity of activities means a situation when the entrepreneur knows the overall direction of international development at the early phases of enterprise functioning. However, there are no plans that would allow them to achieve the unclear visions of goals. As long as the entrepreneur is aware of his or her attempts to achieve 
development, the activities undertaken may be of creative, but at the same time, controlled character. The entrepreneur assesses the opportunities in relevance with the overall direction of international development.

The routines are of repetitive and recognizable character in everyday practice. They are performed by multiple actors that participate in interdependent activities (Feldman \& Pentland, 2003, p. 93). Routines may differ in terms of the variability of reproduced activities. If the variability is relatively high or medium, the activities undertaken on an international scale start to develop into routines and new practice emerges. If the reproduced routines are of low variability, there is an existing practice reproduction. However, as far as this research is concerned with early internationalisation, it may be presumed that the observations here would be adequate to new practice emergence only.

Non-routinised activities are the kind of reaction to changing situational circumstances and opportunities. In terms of early internationalisation non-routinised activities are of reflexive character and stand for the appearance of new international practice emergence.

The Gamma enterprise was operating in the sector of denim apparel until the enterprise encountered the opportunity to launch a different line of production for a partner from Russia (Table 1). The entrepreneur emphasised several times during the interview that is was a kind of a 'shock' for them. Initially, they lacked the knowledge important to pursue new opportunity. The enterprise acted by analogy - they just started work on the templates they had got from their partner. Although it was a new form of working for them, they were able to predict some crucially important details of production since they were relying on their previous experience related to denim textiles. However, their activities were deprived of reflexively and carefully planned strategy of internationalisation. It was a spontaneous decision to enter a new market abroad. As long as the new furniture branch was working on denim materials, they adapted their previous experience to new circumstances and simultaneously, they tried to simplify the process. It is important that interactions with the new partner are based on mutual understanding - I was informed during the interview that the partner was coming to Poland to consult about the production process. The new internationalisation practice emerged as the enterprise entered the new market abroad and launched a new type of products on a regular basis. Thus, the enterprise is not a typical case of early internationalisation, but it started operating in a new branch abroad in 'a quick response' manner. There is a new area that needs further observation in the realms of early internationalisation.

The Theta company creates a new situation on its own in a kind of controlled manner. (Table 1). The medium reflexive activities are focused on learning and innovation-seeking (they launch new product). The practice is developing in the realms of knowing-in-practice i.e. learning through experience and learning by doing: 'everything can be done'. The Theta enterprise is a growing organisation and was internationalised early. It may be done by 'creative destruction' (Schumpeter, 1934) of existing practice and starting the launch of a new product. The fashion brand is fast growing and cyclical. The enterprises create new practice respectively: they develop a product quickly and vary the routines of product development process, however, the lack of distribution resources means that longer time is needed to achieve the results of internationalisation process. Theta controls and guides its actions to some extent. There is intentionality of actions in the realms of making use of knowledge and opportunities. 
The case of the Zeta enterprise represents the high reflexivity of activities at the start of early internationalisation (Table 1). Entrepreneurs intentionally seek to launch the activities abroad. There was a clear vision to cooperate with demanding customers, however, at the beginning Zeta started to seek partners also among design artists. When a highly renowned customer from UK appeared, the entrepreneur intentionally 'jumped at the opportunity'. It is worth noting that the foreign partner found Zeta by chance. That situation initiated the process of learning since up to that time Zeta had no experience in sewing for premium brands: 'Oh, yes, I learnt a lot then. We all did'. The learning process can be considered as the crucial point in regard to high variability of routines. The new practice emerged, and the enterprise has gained key skills crucial to developing products for highly renowned brands.

This study suggests that early internationalisation of SMEs may be perceived through the lens of activities performed daily. I emphasise the importance of having a closer look at daily action patterns of early internationalisation and its potential to unbundle 'the black boxes' (Parmigiani \& Howard-Grenville, 2011) of bigger issues of IE such as: identifying and exploiting opportunities, opportunistic activities, value (co)creation, pro-activeness, and innovativeness. While arguing that there is a relationship between reflexive and routine activities with regard to the early internationalisation process, I find evidence that there are different aspects to reflexivity. On the one hand, reflexivity relies on conscious and, therefore, very often planned activities. On the other hand, such reflexivity stands for a heuristic search for solutions to daily problems. Thus, it is connected with intentionality, even though intentional activities may seem unintended (Makowski, 2016, pp. 177-178). Everyday activities may be difficult to predict, be done by analogy, or stand as bundles of experience and responses to the situational context. Still, they can be treated as reasonable and intentional.

Empirical results show that reflexivity of actions is about references of the conscious mind to interactions, events, everyday use of artefacts and technology, rather than detailed planning. While reflexivity refers to various modes of acting, I find that what can be deemed reflexive acting in the early internationalisation context is highly varied. Moreover, I find that different extent of reflexivity goes hand in hand with differences in the variability of the routines performed daily. The research also takes into account the results of (new) practice emergence with regard to the early internationalisation process. I highlight the following three aspects of the reflexivity of actions: acting by analogy, controlled creation, and intentional seeking. I show that relatively low reflexivity corresponds with the occurrence of unexpected events. The entrepreneur may act using analogies to maintain the daily recreated practice. In fact, people can do this in order to limit the newness of unexpected situations. Here, this observation contributes to the ongoing discourse that questions the pejorative sense of customs and habits as mindless behaviour. In an attempt to trace the very roots of that kind of thinking, we can elaborate on Goffman's idea of dramaturgical action (1959). When people encounter a new activity system, they act using their repertoire of familiar modes of acting. Then, routines appear to be 'something that has to be 'worked at' continually by those who sustain it in their day-to-day conduct' (Giddens, 1984, p. 86). They can be modified or their change can evolve into a completely new category of activities reproduced daily (Stańczyk-Hugiet et al., 2017). This study demonstrates how relatively low reflexivity 
Table 1. Reflexive and routine activities in the early internationalisation process

\begin{tabular}{|c|c|c|c|}
\hline Categories & Intensity & Description & Illustrative data \\
\hline \multicolumn{4}{|c|}{$\begin{array}{llllllllllllll}G & A & M & M & A & E & N & T & E & R & P & R & I & S\end{array}$} \\
\hline $\begin{array}{l}\text { Reflexivity of } \\
\text { actions } \\
\text { Subcategories: } \\
\text { acting through } \\
\text { analogy }\end{array}$ & Low & $\begin{array}{l}\text { Starting services for a customer operating in the furniture } \\
\text { industry was a new, unexpected situation and context of } \\
\text { new artefacts, aesthetic and technical forms. At the very } \\
\text { beginning they lacked proper knowledge that could be } \\
\text { basis of routines. During the interview, the term } \\
\text { 'flexibility' is contrasted by the company owner with } \\
\text { simplicity of sewing denim sofa covers and therefore, } \\
\text { there are some analogies in production activities. }\end{array}$ & $\begin{array}{l}\text { 'The first time. They were completely different, some } \\
\text { structures, huge... and then you just put it on. (...)You } \\
\text { have to be flexible, otherwise you won't make it (...) } \\
\text { We simply sew such covers for the sofas and then they } \\
\text { put it on the frame.' }\end{array}$ \\
\hline $\begin{array}{l}\text { Variability of } \\
\text { routines }\end{array}$ & High & $\begin{array}{l}\text { The new mode of performing activities resulted in high } \\
\text { variability of reproduced routines. However, the new line } \\
\text { of production was fast routinised. As a result, it } \\
\text { broadened the company's scope of operating abroad. }\end{array}$ & $\begin{array}{l}\text { 'We cooperate with a company manufacturing } \\
\text { furniture'. }\end{array}$ \\
\hline $\begin{array}{l}\text { Internationalis } \\
\text { ation practice }\end{array}$ & Emergence & $\begin{array}{l}\text { The new practice emergence was radical, quick and it has } \\
\text { been urged by the partner who is also entering the } \\
\text { Russian market. }\end{array}$ & $\begin{array}{l}\text { 'This year they went to some fair because we } \\
\text { manufactured a lot (...) Now they found some } \\
\text { customer from Russia. (...) } \\
\text { We all thought for some time that everyone got bored } \\
\text { with this, but surprisingly a new market appeared'. }\end{array}$ \\
\hline \multicolumn{4}{|c|}{$\begin{array}{lllllllllllllllllll}T & \mathrm{H} & \mathrm{T} & \mathrm{A} & \mathrm{E} & \mathrm{N} & \mathrm{T} & \mathrm{E} & \mathrm{R} & \mathrm{P} & \mathrm{R} & \mathrm{S} & \mathrm{E}\end{array}$} \\
\hline $\begin{array}{l}\text { Reflexivity of } \\
\text { activities } \\
\text { Subcategories: } \\
\text { Controlled } \\
\text { creation } \\
\text { activities }\end{array}$ & Medium & $\begin{array}{l}\text { The Theta enterprise takes new opportunities to develop. } \\
\text { They create new activities as well as new situations, } \\
\text { however, there is no clear vision of goals. Entering foreign } \\
\text { markets requires very different products and new } \\
\text { distribution channels. The main product is reoriented and } \\
\text { redesigned. }\end{array}$ & $\begin{array}{l}\text { The case of stating to sell products abroad: } \\
\text { '...everything can be done, for example, } \\
\text { we now have those tank tops (...) which don't include } \\
\text { any Polish characters'. }\end{array}$ \\
\hline $\begin{array}{l}\text { Variability of } \\
\text { routines }\end{array}$ & Medium & $\begin{array}{l}\text { The variability of routines is based on the readiness to } \\
\text { create new communication forms, although it is still in the } \\
\text { process. Although the enterprise is growing fast and it still } \\
\text { seeks new products and markets. }\end{array}$ & $\begin{array}{l}\text { '(...) but perhaps there will be some distribution (...) } \\
\text { Well, Bread and Butter, Bright, fairs of this kind...' }\end{array}$ \\
\hline
\end{tabular}




\begin{tabular}{|c|c|c|c|}
\hline Categories & Intensity & Description & Illustrative data \\
\hline $\begin{array}{l}\text { Internationalis } \\
\text { ation practice }\end{array}$ & $\begin{array}{l}\text { Emergence in } \\
\text { process }\end{array}$ & $\begin{array}{l}\text { The controlled creation mode of routinisation is time- } \\
\text { consuming. On the other hand, it needs some radical } \\
\text { changes like launching new products. } \\
\text { The semi-emergent process is based on mixing radical } \\
\text { conceptual solutions with the process of searching new } \\
\text { ways of exploring the foreign markets }\end{array}$ & $\begin{array}{l}\text { 'We just follow our nose. (...) You know, this is only a } \\
\text { kind of a plan. It's not that we... This is a plan for, let's } \\
\text { say, the next two years'. }\end{array}$ \\
\hline \multicolumn{4}{|c|}{$\begin{array}{lllllllllllllll}Z & E & T & A & E & N & T & E & R & P & R & I & S & E\end{array}$} \\
\hline $\begin{array}{l}\text { Reflexivity of } \\
\text { activities } \\
\text { Subcategories: } \\
\text { intentional } \\
\text { seeking } \\
\text { activities }\end{array}$ & High & $\begin{array}{l}\text { The entrepreneur's clear intention was to perform } \\
\text { services not previously offered to foreign customers. Zeta } \\
\text { wanted to cooperate with more demanding customers, } \\
\text { however, at the beginning there was a vison of } \\
\text { cooperating with design artists. After that, a premium } \\
\text { brand international company found Zeta. }\end{array}$ & $\begin{array}{l}\text { Question: Have you always planned or maybe dreamt } \\
\text { about this cooperation with designers?' } \\
\text { Zeta: 'More than that, I have been striving to achieve } \\
\text { the cooperation for a long time. I attended trade fairs, } \\
\text { I even looked for contacts in our Academy of Fine Arts, } \\
\text { and it apparently worked after many years, they now } \\
\text { find me more easily'. } \\
\text { The situation of starting the cooperation with a } \\
\text { premium brand company: 'He was looking for, I don't } \\
\text { know, a company in Poland at the time (...)Oh, yes, I } \\
\text { learnt a lot then. We all did'. }\end{array}$ \\
\hline $\begin{array}{l}\text { Variability of } \\
\text { routines }\end{array}$ & Medium & $\begin{array}{l}\text { It was crucial for the enterprise to develop some unique } \\
\text { resources - skills and routines that stand for the } \\
\text { enterprise's comparativeness in the international } \\
\text { markets. Orientation towards cooperation with foreign } \\
\text { premium brands was directed towards the variability of } \\
\text { routines at the very beginning. When the routines } \\
\text { achieved a certain degree of excellence, they became a } \\
\text { standard of daily operations. }\end{array}$ & $\begin{array}{l}\text { The example of finishing works:'(...) it's standard here } \\
\text { now, but at first we were also surprised: how can you } \\
\text { find fault with one small thread that you can't even see } \\
\text { because it's hidden, but now...' }\end{array}$ \\
\hline $\begin{array}{l}\text { Internationalis } \\
\text { ation practice }\end{array}$ & Emergence & $\begin{array}{l}\text { Intentional seeking resulted in new practice emergence, } \\
\text { however, it was connected here with a relatively long } \\
\text { learning process and opportunism. The working phase for } \\
\text { the product required standards that were comparatively } \\
\text { innovative at the time the operations abroad started. }\end{array}$ & $\begin{array}{l}\text { '(...) And these are appliquéd fabrics, or other solutions } \\
\text { are added... That's it. A lot of Swarovski elements... at } \\
\text { that time Swarovski wasn't as well-known as it is } \\
\text { today'. }\end{array}$ \\
\hline
\end{tabular}

Source: author's own and on the basis on Z. Patora-Wysocka (2016a, 2016b, 2017). 
of actions leads to international market expansion. On the other hand, this study also provides an example of how relatively high reflexivity of actions - still under unpredictable circumstances - can result in launching a new internationalisation practice. Clearly defined goals can fuel opportunism as well as heuristic and, at the same time, 'intentional seeking' activities. Such acting meets the criteria of learning behaviour followed by medium variability of routines undergoing gradual changes until they establish a standard of the operations performed daily on an international scale. In this context, I present some evidence of new internationalisation practice emergence.

Finally, this work contributes to the understanding of medium reflexivity of actions that is accompanied by controlled creation activities. Therefore, an entrepreneur who is only at the beginning of the internationalisation process, can only be aware of the general direction of development. While the routines that are newly established in the domestic market may prompt the very first market success, they may also be creatively destroyed (Schumpeter, 1934) when getting into the international market. Lack of detailed plans how to achieve new goals appears to trigger a new mode of acting with regard to early internationalisation.

\section{CONCLUSIONS}

The practice-based perspective offers more profound understanding of the basic categories of entrepreneurship such as pro-activeness, innovativeness, opportunism, and risk-taking, as long as it tackles the 'how' research question. When looking at IE as a stream of activities, it is crucial to take into account capabilities, past experience, situational context, interactions, as well as modes of acting and taking decisions. The reflexive actions and routines can serve as explanatory categories of an early internationalisation process. The routines, increasingly, are perceived as changeable and dynamic collectives that are of twofold character. They bring together the basic aspects of organisational persistence and change. The recurrent activity schemas allow entrepreneurs to sustain a competitive advantage on the domestic market and explore opportunities to launch the activity abroad.

Notwithstanding my efforts to identify the relationships between reflexive and routine activities within the early internationalisation process, there are several limitations that otherwise might constitute interesting future research avenues. Firstly, I observed a specific issue in a particular group of enterprises, i.e. textile and apparel enterprises. This sector is, by definition, highly impacted by fashion phenomena that impose a certain pace of changes on the product development cycle. Another limitation of this study is that it discovered only three subcategories of reflexive activities as regards early internationalisation. Therefore, one could ask if the array of possible subcategories of reflexive activities is open to further exploration. Even though my research did not take the newly emerged question into theoretical or empirical account, I believe that this work contributes to the deeper understanding of the early internationalisation process, and that it sheds some new light on its potential explanatory categories.

In practical terms the research indicates that much depends on the reflexivity of entrepreneurs and in fact, it is the basis for crucial recommendation for them. During my interviews people often realized that some of the important activities were taken in an unplanned manner. Thus, the awareness of the interplay between everyday routines and reflexive activities may add to the effects of everyday business. 


\section{REFERENCES}

Amorós, J.E., Rodrigo Basco, R., \& Romaní, G. (2016). Determinants of early internationalization of new firms: the case of Chile. International Entrepreneurship and Management Journal, 12(1), 283-307. https://doi.org/10.1007/s11365-014-0343-2

Aspelund, A., \& Moen, $\varnothing$. (2005). Small international firms: Typology, performance and implications. Management International Review, 1(1), 37-57.

Autio, E. (2005). Creative tension: The significance of Ben Oviatt's and Patricia McDougall's article "Towards a theory of international new ventures". Journal of International Business Studies, 36(1), 9-19. https://doi.org/10.1057/palgrave.jibs.8400117

Baum, M., Schwens, Ch., \& Kabst, R. (2011). International as opposed to domestic new venturing: The moderating role of perceived barriers to internationalization. International Small Business Journal, 31(5), 536-562. https://doi.org/10.1177/0266242611428343

Deken, F., Carlile, P.R., Berends, H., \& Lauche, K. (2016). Generating novelty through interdependent routines: A process model of routine work. Organization Science, 27(3), 659-677. https://doi.org/10.1287/orsc.2016.1051

Dittrich, K., Guérard, S., \& Seidl, D. (2016). Talking About Routines: The Role of Reflective Talk in Routine Change. Organization Science, 27(3), 678-697. https://doi.org/10.1287/orsc.2015.1024

Etemad, H. (2015). The promise of a potential theoretical framework in international entrepreneurship: An entrepreneurial orientation-performance relation in internationalized context. Journal of International Entrepreneurship, 13(2), 89-95. https://doi.org/10.1007/s10843-015-0157-5

Feldman, M.S., \& Pentland, B.T. (2003). Reconceptualizing Organizational Routines as a Source of Flexibility and Change. Administrative Science Quarterly, 48(1), 94-118. https://doi.org/10.2307/3556620

Feldman, M.S., Pentland, B.T., D’Adderio, L., \& Lazaric, N. (2016). Beyond Routines as Things: Introduction to the Special Issue on Routine Dynamics. Organization Science, 27(3), 505-513. https://doi.org/10.1287/orsc.2016.1070

García-Cabrera, A.M, García-Soto M.G., \& Suárez-Ortega S.M. (2017). Macro-level spillovers and micro-level capabilities as antecedents of young SMEs' propensity to export and to become a born global. International Entrepreneurship Management Journal, 13(4), 1199-1122. https://doi.org/10.1007/s11365-017-0451-x

Gavetti, G., Levinthal, D.A., \& Rivkin, J.W. (2005). Strategy making in novel and complex worlds: the power of analogy. Strategic Management Journal, 26(8), 691-712. https://doi.org/10.1002/smj.475

Giddens, A. (1984). The constitution of society: Outline of the theory of structuration. Berkeley: California University Press.

Goffman, E. (1959). The Presentation of Self in Everyday Life. Garden City, NY: Doubleday.

Hamil, H. (2014). Interview Methodology. Oxford Bibliographies. Oxford: Oxford University Press.

Keupp, M.M, \& Gassmann, O. (2009). The Past and the Future of International Entrepreneurship: A Review and Suggestions for Developing the Field. Journal of Management, 35(3), 600-633. https://doi.org/10.1177/0149206308330558

Liesch, P.W., Welch, L.S., \& Buckley, P.J. (2011). Risk and Uncertainty in Internationalisation and International Entrepreneurship Studies Review and Conceptual Development. Management International Review, 51(6), 851-873. https://doi.org/10.1007/s11575-011-0107-y

Makowski, P.T. (2016). Tadeusz Kotarbiński's Action Theory. Reinterpretive Studies, Cham: Palgrave Macmillan. 
Miller, D. (1983). The correlates of entrepreneurship in three types of firms. Management Science, 29(7), 757-868. https://doi.org/10.1287/mnsc.29.7.770

Oviatt, B.M., \& McDougall, P.P. (2005). The internationalization of entrepreneurship. Journal of International Business Studies, 36(1), 2-8. https://doi.org/10.1057/palgrave.jibs.8400119

Parmigiani, A., \& Howard-Grenville, J. (2011). Routines revisited: Exploring the capabilities and practice perspectives. Academy of Management Annals, 5(1), 413-453. https://doi.org/ 10.1080/19416520.2011.589143

Patora-Wysocka, Z. (2016a). Institutionalization of Practice: A Processual Perspective on Value Co-Creation. Economics and Business Review, 2(16), 113-126. https://doi.org/10.18559/ebr.2016.2.7

Patora-Wysocka, Z. (2016b). The Twofold Nature of Spontaneous Actions: Insights From Practice Turn In Management. Studia Oeconomica Posnaniensia, 4(5), 184-198. https://doi.org/10.18559/SOEP.2016.5.11

Patora-Wysocka, Z. (2017). Beyond Stability vs. Change Dilemma: Everyday Practices and Routines as Sources of Organizational Life. Entrepreneurial Business and Economics Review, 5(1), 201212. https://doi.org/10.15678/EBER.2017.050112

Pentland, B.T., \& Jung Ju, E. (2016). Evolutionary and Revolutionary Change in Path-Dependent Patterns of Action. In J. Howard-Grenville, C. Rerup, A. Langley, \& H. Tsoukas (Eds.), Organizational Routines: How They are Created, Maintained, and Changed (pp. 96-116). Oxford: Oxford University Press.

Saladaňa, J. (2013). The Coding Manual for Qualitative Researchers. London: SAGE Publications Ldt.

Schumpeter, J. (1934). The Theory of Economic Development. Cambridge, MA: Harvard University Press.

Styles, C., \& Seymour, R.G. (2006). Opportunities for marketing researchers in international entrepreneurship. International Marketing Review, 23(2), 126-145. https://doi.org/10.1108/02651330610660056

Stańczyk-Hugiet, E., Piórkowska, K., \& Stańczyk, S. (2017). Demystifying emergence of organizational routines. Journal of Organizational Change Management, 30(4), 525-547. https://doi.org/10.1108/JOCM-03-2016-0048

Thurner, T.W., Gershman, M., \& Roud, V. (2015). Partnerships as internationalization strategy: Russian entrepreneurs between local restrictions and global opportunities. Journal of International Entrepreneurship, 13(2), 118-137. https://doi.org/10.1007/s10843-015-0146-8

Weick, K. (1995). Sensemaking in Organizations. Thousand Oaks, CA: Sage. 


\section{Authors}

\section{Zofia Patora-Wysocka}

$\mathrm{PhD}$ in Management (Politechnika Częstochowska). Her research interests include organisational change management, international entrepreneurship, organisation and management theory, organisational behaviour.

Correspondence to: dr Zofia Patora-Wysocka, University of Social Sciences in Łódź, Departament of Management, ul. Sienkiewicza 9, 90-113 Łódź, Poland, e-mail: zpatora-wysocka@san.edu.pl

\section{Acknowledgements and Financial Disclosure}

The author is grateful to anonymous reviewers for their incredibly constructive comments. The article was written as part of the project no. DEC-2011/03/D/HS4/01651 entitled "Internationalisation as a factor initiating change in the enterprise" financed by the National Science Centre and conducted by the University of Social Sciences in the years 2012-2016.

\section{Copyright and License}

This article is published under the terms of the Creative Commons

Attribution - NoDerivs (CC BY-ND 4.0) License http://creativecommons.org/licenses/by-nd/4.0/

\section{Published by the Centre for Strategic and International Entrepreneurship - Krakow, Poland}


